\title{
AS REGIÕES GOIANAS SOB O ASPECTO DA NOVA DIVISÃO GEOGRÁFICA DO IBGE: O FORMAL E O REAL, O IMEDIATO E O INTERMEDIÁRIO
}

\author{
Marcos Bittar Haddad ${ }^{1}$
}

RESUMO: A dinâmica econômica presente em Goiás, além de possuir tradições rurais/agrícolas, que impulsionam a prática do agronegócio, também é impulsionada por uma crescente industrialização, motivada, sobretudo, por ser Goiás, um dos estados mais agressivos na atração de investimentos privados, via os incentivos fiscais. $O$ estado passa por uma ocupação produtiva que cria regiões dinâmicas e que, em hipótese, necessariamente não estejam influenciadas ou conectadas diretamente à sua capital, onde se localiza a única Região Metropolitana do estado. Pode-se tratar de uma dinâmica econômica conectada diretamente pelo capital externo, pois esta é a lógica presente no agronegócio. Entender a configuração da divisão regional goiana conforme o novo recorte proposto pelo IBGE, em 2017, que define regiões imediatas e regiões intermediarias, passa por uma investigação, se estas regiões intermediárias, criadas a partir desta nova metodologia, que define uma nova divisão regional, surgem de novas áreas dinâmicas independentes da RMG ou se estas regiões são áreas de extensão da capital. Este trabalho, que pode ser classificado como um ensaio, parte inicialmente, da reprodução da literatura já existente sobre os diversos conceitos e definições para local, regional, espaço, ou seja, das diferentes abordagens que definem a espacialização a fim de justificar que esta nova metodologia, proposta pelo IBGE, pode ser o que melhor explica a região como algo que não deve possuir barreiras, mas pode se expandir para além do que está formalmente delimitado.

Palavras-Chave: Planejamento Regional. Desenvolvimento. Dinâmicas Econômicas

ABSTRACT: The economic dynamics present in Goiás, besides having rural / agricultural traditions, which drive the practice of agribusiness, is also driven by a growing industrialization, motivated mainly by being Goiás, one of the most aggressive states in attracting private investments via tax incentives. The state goes through a productive occupation that creates dynamic regions and that, in hypothesis, are not necessarily influenced or connected directly to its capital, where the only Metropolitan Region of the state is located. It can be an economic dynamic connected directly by external capital, as this is the logic present in agribusiness. Understanding the configuration of the Goiás regional division, according to the new cut proposed by IBGE in 2017, which defines immediate regions and intermediate regions, is an investigation, if these intermediate regions, created from this new methodology, which defines a new regional division, arise from new dynamic areas independent of the RMG or whether these regions are areas of extension of the capital. This research, which can be

${ }^{1}$ Doutorado em Desenvolvimento Econômico pela UNICAMP. Professor Titular da Faculdade Nossa Senhora Aparecida. E-mail: haddad13@gmail.com 
classified as an essay, starts from the reproduction of the existing literature on the different concepts and definitions for local, regional, space, that is, the different approaches that define spatialization in order to justify that this new methodology, proposed by the IBGE, may be what best explains the region as something that should not have barriers, but can expand beyond what is formally defined.

Keywords: Regional Planning. Development. Economic Dynamics.

\section{INTRODUÇÃO}

Formalmente Goiás possui uma única Região Metropolitana, que engloba sua capital, Goiânia, e suas proximidades, composta por 20 municípios onde nem todos estão aglomerados à capital. Estudos anteriores, como o REGIC/IBGE 2007, classifica Goiânia como capital regional, com extensa área de influência, que vai além do próprio território goiano.

É sabido que no estado de Goiás, existem outras áreas dinâmicas, além da RM formal, como a cidade de Anápolis, a região próxima ao Distrito Federal (Ride), o sudoeste do estado (Rio Verde), forte no agronegócio e a região sul do estado (Catalão e Itumbiara), aonde a exploração mineral e a indústria tem transformado a realidade.

Além da RM e das regiões com suas cidades polo, formalmente o estado de Goiás sempre fora estudado por sua divisão regional comporta por cinco macrorregiões e dezoito microrregiões, além das regiões administrativas estimadas pelo governo estadual, que se modicou muito ao longo do tempo, tendo finalmente seguido a proposta do IBGE nessa divisão de macro e microrregiões.

Pelos dados da dinâmica econômica, seja pela geração de empregos e renda (RAIS) ou pela geração de riquezas (PIB), a RM de Goiânia sempre foi a que liderou todo o processo de crescimento econômico de Goiás. As demais regiões formais, estabelecidas pela divisão regional, interligam-se à Goiânia e sua RM, pois é a capital que, desde que desde a década de 1950, comanda as atividades econômicas no estado.

A dinâmica econômica presente em Goiás, além de possuir tradições rurais/agrícolas, que impulsionam a prática do agronegócio, também é impulsionada por uma crescente industrialização, motivada, sobretudo, por ser Goiás um dos estados 
mais agressivos na atração de investimentos privados via os incentivos fiscais. A vinda de indústrias para o estado, em troca de uma baixa tributação (IPTU e ICMS), tem modificado a realidade agraria e criado novas dinâmicas.

Desta maneira, o estado de Goiás passa por uma ocupação produtiva que cria regiões dinâmicas e que, em hipótese, necessariamente não estejam influenciadas ou conectadas diretamente à sua capital, onde se localiza a única Região Metropolitana do estado. Pode-se tratar de uma dinâmica econômica conectada diretamente pelo capital externo, pois esta é a lógica presente no agronegócio.

Como sabido, a localização geográfica central, faz de Goiás, ao longo de sua história, um receptor de imigrações e investimentos públicos e privados. Sobretudo os investimentos privados, em sua imensa maioria, provocados pelos incentivos fiscais, não são originários de Goiás, o que faz crer que esta dinâmica econômica esteja atrelada a centros maiores de decisão, como, por exemplo, o estado de São Paulo. Caso isso se comprove, as regiões intermediárias definidas pelo IBGE não estariam atreladas à Goiânia.

Entender a configuração da divisão regional goiana conforme o novo recorte proposto pelo IBGE, em 2017, que define regiões imediatas e regiões intermediarias, passa por uma investigação, se estas regiões intermediárias, criadas a partir desta nova metodologia, que define uma nova divisão regional, surgem de novas áreas dinâmicas independentes da RMG ou se estas regiões são áreas de extensão da capital.

Este trabalho, que pode ser classificado como um ensaio, parte inicialmente, da reprodução da literatura já existente sobre os diversos conceitos e definições para local, regional, espaço, ou seja, das diferentes abordagens que definem a espacialização a fim de justificar que esta nova metodologia, proposta pelo IBGE, pode ser o que melhor explica a região como algo que não deve possuir barreiras, mas pode se expandir para além do que está formalmente delimitado.

Em seguida, a partir de estudos já realizados sobre as diversas dinâmicas econômicas, presentes em Goiás, tenta-se explicar o processo de formação do território goiano pela lógica da ocupação pelo capital, que definiu as regiões dinâmicas que resultou nas diversas divisões regionais pelas quais o estado passou. 
Por fim, utilizando de dados secundários, como PIB e RAIS, procurar-se demonstrar cada região entendida como imediata e intermediaria existente dentro do estado de Goiás, verificando sua conexão com a RM formal existente.

\section{O ESPAÇO, O LOCAL, O REGIONAL: DIFERENTES ABORDAGENS PARA IDENTIFICAR O LUGAR}

As diversas ciências abordam o conceito de região à sua maneira. De forma geral, na geografia, economia ou ciências sociais, as justificas atendem as funções de objetivos e finalidades diversas. A geografia é a ciência que define exatamente o conceito de região. A economia, utiliza as divisões da geografia para propor o desenvolvimento regional.

Historicamente, a denominação de região surgiu no Império Romano, quando o termo regione era utilizado para delimitar um espaço, estando ou não, este local, subordinado ao Império. O termo região serviu então para marcar a delimitação entre a centralização do poder de um local e a extensão dele, sobre uma área de grande diversidade social, cultural e espacial.

Para a geografia, outros conceitos de natureza espacial, também são usados, desde a época do Império Romano: Spatium - espaço - visto como contínuo ou como intervalo, onde estão disposto s os corpos, que seguem alguma ordem dentro do vazio e Pronvicere - província - espaço submetido ao domínio da ordem hegemônica dos romanos.

O fim do Império Romano possibilitou o processo de fragmentação regional, desembocando num poder descentralizado de territórios regionais do período feudal. Porém, a problemática da política regional é resgatada, com a centralização do poder no Estado Moderno Europeu, "da manutenção do poder que emana de um centro, muitas vezes distante de suas periferias, nas diversas regiões que formam o território de um determinado Estado" (CUNHA, 2000, p. 41-42).

Gomes (1995) conclui que "o conceito de região permitiu, em grande parte, o surgimento das discussões políticas sobre a dinâmica do Estado, a organização da cultura e o estatuto da diversidade espacial; o debate sobre o conceito permitiu também 
a incorporação da dimensão espacial nas discussões relativas à política, cultura e economia, e no que se refere às noções de autonomia, soberania, direitos, etc.; e, por último, foi na Geografia que as discussões atingiram maior importância, já que região é um conceito - chave desta ciência".

Para Markusen (1987), "regiões são criaturas multifacetadas da história, produtos das mudanças contemporâneas e domicílios de grupos diversos, que nos interessam porque são locais do drama humano". Para esta autora, na preocupação de conceituar região, deve-se "não enfatizar apenas um aspecto particular da realidade e buscar preservar em termos analíticos seu sentido histórico" (PACHECO, 1998, p. 34).

Markusen ainda elabora uma segunda observação: "regiões, enquanto territórios econômicos funcionam como uma organização produtiva. Isto é, elas são o lócus de conjuntos de atividades econômicas inter-relacionadas, as quais incorporam trabalho assalariado na produção de mercadorias para troca." (PACHECO, 1998, p. 38). Este certamente é um conceito que permite ver que as diversas regiões são diferentes umas das outras. Uma região possui vários determinantes, inclusive a especialização setorial. Cada uma de suas especialidades, dita sua característica e sua dinâmica econômica.

Lipietz faz críticas às concepções abstratas de espaço da economia regional, tendo uma visão social deste espaço. Para ele, "não se deve analisar regiões, mas a dimensão social dos espaços sociais" (PACHECO, 1998, p. 28). Como sendo uma formulação da problemática marxista, para Lipietz, o espaço socioeconômico tem duas dimensões: uma como reflexo das articulações sociais e outra como um constrangimento objetivo impondo ao desenvolvimento destas relações. Deste modo, "a região aparece assim como o produto das relações inter-regionais e estas como uma dimensão das relações sociais" (LIPIETZ, 1988: 29, apud PACHECO, 1998, p. 28).

Ainda na visão de Lipietz, o desenvolvimento desigual é resultante da acumulação do capital, sendo que de um lado está o produto histórico de articulações do modo de produção e, do outro, o desdobramento do capital monopolista. Lipietz insiste que "não se deve cair na ilusão estruturalista: o espaço seria a dimensão espacial das relações sociais e, portanto, da luta de classes." (PACHECO, 1998, p. 29). 
Para criticar o uso da economia política, Mark Gottdiner referindo-se ao urbano, parte desta problemática para teorizar o espaço como produto do capital. Também Lefebvre e Castells, confrontam em suas abordagens de conceito para região. Ambos ressaltam a importância histórica, também reforçada por Gottdiner, não incorrendo em diversos reducionismos, das tentativas marxistas de pensar o espaço.

A dificuldade de se ter uma resolução para tais conceitos, "transparece no que postula como seu paradigma alternativo: padrões de ocupação do espaço produzidos pelo organismo social, inclusive pelo Estado, mas sem que as relações capitalistas estejam diretamente refletidas nas formas urbanas e incorporando determinações outras, tais como fenômenos ideológicos, políticos e culturais, situando seus determinantes muito aquém da problemática do desenvolvimento urbano." (PACHECO, 1998, p. 32).

O que se pode perceber, é que tanto na Geografia como na Economia, existe uma polêmica acerca do conceito de região e de uma proposta de viabilização para o desenvolvimento econômico. O certo mesmo é considerar que para a maioria dos geógrafos, assim como economistas e sociólogos, estas definições não possuem conceitos exclusivos e definitivos. Eles são dinâmicos e dificilmente poderá haver consenso para um conceito único no que se refere ao paradigma de região.

Portanto, como afirma Firkowski (2010) "discutir o território não é tarefa simples e tampouco exclusiva de uma área do conhecimento (...) nos últimos anos, a preocupação e as formulações acerca do território ganharam destaque em várias áreas do saber, com ênfase na Geografia, Economia, Sociologia, Arquitetura e Urbanismo, e História".

\section{CARACTERIZAÇÃO ECONÔMICA DO TERRITÓRIO GOIANO}

No Brasil, o Estado teve o papel de, juntamente com os demais agentes sociais, realizar a abertura de novas áreas para a expansão de capitais. Para isso, expandiu fronteiras, abriu estradas, criou lugares, ampliou e incrementou a produção de bens, transformando-os em mercadorias, implantando instituições, foi o ente principal que se encarregou de administrar e promover a integração dos mercados (BORGES, 2004). E, 
assim, o Estado se materializou nas diversas partes do país e, no caso de Goiás, foi o setor público que promoveu "a abertura e a ocupação da fronteira atraindo maciça imigração e investimentos para a região" (ESTEVAM, 2004, p. 111). Foi com a ampliação da fronteira e integração do mercado interno que se intensifica a inserção de Goiás no processo da economia nacional.

A localização geográfica de Goiás o torna rota obrigatória no deslocamento de mercadorias entre determinadas partes do país. Seu território pode ser usado como alternativa para acessar outros territórios em menor espaço de tempo. A sua localização central o torna importante no comércio interestadual, em trânsito e, ainda, para o comércio com vários países sul-americanos (SEINFRA, 2007). Por isso, o território goiano pode ser considerado um centro logístico, o que requer investimentos em infraestrutura de transportes para ser consolidado como rota de escoamento de mercadorias.

Nesse sentido, as políticas implementadas pelo governo federal foram o que mais contribuiu para o desenvolvimento de Goiás. Seja na criação de novas cidades no interior de seu território ou nas políticas de incentivos à ocupação das terras, no interior do Brasil, para ampliação da produção agrícola, em meados do século XX.

Até 1930, a economia goiana caracterizava-se pela baixa divisão social do trabalho. A atividade econômica era predominantemente rural, baseada na agricultura de subsistência e com pouca circulação comercial e monetária. Sua realidade não acompanhava o desenvolvimento que ocorria no restante do país, que já se abria ao processo de industrialização, liderado por São Paulo.

O processo de modernização agrícola que ocorria paralelo ao surgimento da indústria, na parte sul do Brasil, não chegara a Goiás. Um dos motivos para que isso ocorresse foi a falta de estradas que deixava o estado desconectado do restante do país. O Governo estadual não possuía recursos para abrir estradas, seria preciso recorrer ao Governo Federal, mas, para isso, o estado não contava com expressão política para conseguir a vultuosa quantidade de recursos necessários (SIQUEIRA, 2009).

Após a implantação do Estado Novo, em 1930, surgiu a preocupação de integrar o território nacional. Foi a partir daí que Goiás foi inserido no planejamento federal. A 
primeira intervenção estatal no território goiano, que foi um fator que motivou todo o processo de crescimento econômico e social que veio a seguir, foi a Marcha para o Oeste. Este Programa, que ocorreu entre 1937 e 1945, buscou unificar o país politicamente e economicamente. Conquistar o Oeste significava enviar para a região pessoas e investimentos, a fim de chegarem até a Amazônia, integrando "nova áreas ocupando-as e tornando-as produtivas, em conformidade com o padrão de acumulação imposto pela industrialização em franco andamento no Sudeste" (BORGES, 2004, p. 190). Como ação imediata, foi implantada a Colônia Agrícola Nacional de Goiás (CANG). Esta foi a primeira experiência de colonização e a mais bem-sucedida entre todas que foram implantadas posteriormente.

Localizada onde hoje estão as cidades de Ceres e Rialma, no centro norte de Goiás, a CANG recebeu colonos de várias partes do Brasil, que passaram a produzir, sobretudo, arroz em terras doadas pelo governo federal. Por seu caráter colonizador, a CANG levou para Goiás um grande número de imigrantes2. Outras intervenções que contribuíram para as transformações econômicas e estruturais ocorridas no interior do território goiano foram a edificação da nova capital, Goiânia (1933 a 1942) e, posteriormente, a de Brasília (1955 - 1960), a nova capital federal.

Goiânia é considerada o marco inicial da Marcha para o Oeste, pois deflagrou o processo de implantação de infraestrutura para interligar o estado com o restante do país. Mas esta interligação só foi efetivamente realizada anos depois, com a edificação de Brasília. A nova capital fez surgir um pacote de programas federais, dentre eles, diversas rodovias que ligavam o território goiano com todas as partes do Brasil e até com o exterior.

Além disso, programas que promoveram o fortalecimento dos solos, dando condições para o surgimento de uma agricultura e pecuária que se tornariam uma das mais fortes do país. Foram ações que contribuíram para ampliar as migrações,

\footnotetext{
${ }_{2}^{2}$ As notícias de solo fértil e apoio do Estado Novo atraíram, para a CANG, muitos agricultores. Em 1943, eram 900 ocupantes. A partir de 1946, cerca de 30 famílias chegavam diariamente à Colônia. Em 1947, mais de dez mil pessoas habitavam a CANG. Esta população crescia rapidamente e, em 1950, era de 29.522 pessoas. Em 1953, este número já era de 36.672 , com $90,6 \%$ residindo na zona rural. A maioria dessas pessoas (6\%) era proveniente de Minas Gerais. O restante vinha do próprio estado de Goiás, de São Paulo, Rio Grande do Sul e dos estados da Região Norte (CASTILHO, 2009).
} 
permitindo surgir novas centralidades, Como Anápolis, Catalão, Itumbiara e Formosa, localizadas no centro sul, região onde está Goiânia e nos arredores do Distrito Federal.

Por sua localização geográfica, no centro do Brasil, o estado permite facilmente sua interligação com diversas regiões, sendo um privilegiado entreposto logístico. A implantação das rodovias favoreceu o surgimento de vários centros urbanos e comerciais nas suas diversas regiões. O próprio desenvolvimento de Goiânia, que se destaca como uma das mais importantes cidades do centro norte do Brasil, ocorreu após o surgimento de Brasília e das rodovias. No centro do Estado, Anápolis destacase como importante centro comercial e urbano. No Sul, as cidades de Catalão, Rio Verde, Jataí e Itumbiara polarizam a produção e comercialização da importante cadeia do agronegócio, existente na Região Centro-Oeste. Próximo ao Distrito Federal, desenvolveram-se cidades como Luziânia, Formosa e Águas Lindas, que concentram população e atividades de serviços para atender Brasília. Para o norte, tem-se Uruaçu e Porangatu, que se desenvolveram com a BR 153 e tornaram-se importantes centros comerciais.

A importância logística que Goiás ocupa dentro do Brasil levou também, o Governo estadual a implantar estruturas que buscavam atrair para o estado maiores investimentos. A principal delas é a Plataforma Logística Multimodal, localizada na cidade de Anápolis. Essa plataforma uniria, numa mesma localidade, rodovias, ferrovias e aeroporto de cargas, buscando consolidar o Estado como importante centro logístico.

Além de centro logístico, Goiás também pode ser considerado importante polo de prestação de serviços e fornecimento de bens e insumos, sobretudo para atender à intensa atividade do agronegócio localizado no interior do Brasil. Cidades como Goiânia, Aparecida de Goiânia, Anápolis e Rio Verde concentram sedes de empresas pertencentes à cadeia produtiva do agronegócio, que atendem ao próprio estado e aos demais da região Centro - Oeste, e parte do Norte e Nordeste. Estas cidades ocupam esta posição porque foram as que melhor desenvolveram a rede comercial e de serviços de alto padrão, exigidos pela cadeia do agronegócio ${ }^{3}$.

\footnotetext{
${ }^{3}$ Anápolis, desde os tempos da CANG, e depois com a chegada da ferrovia, se consolidou como importante centro comercial da Região Centro Norte. Rio Verde foi uma das primeiras cidades da Região Centro Oeste a receber investimentos para potencializar o agronegócio, o que dotou a cidade de infraestrutura que serve de suporte para outras cidades.
} 
Goiânia, a capital de Goiás, pode ser considerada a mais importante cidade do Centro Oeste (depois de Brasília, que possui importância política por ser a capital federal) e é detentora de importante polo de serviços, com destaque para o segmento de saúde que não atende apenas aos estados da região Centro - Oeste, mas também, das Regiões Norte, Nordeste e parte do Sul e Sudeste. A cidade de Goiânia é referência em algumas especialidades médicas, como oftalmologia, cardiologia, neurologia, oncologia e recuperação de queimados, e, juntamente com Anápolis, forma um importante polo educacional. A Universidade Federal de Goiás (UFG), sediada em Goiânia, e a UEG, com sede em Anápolis, com campis situados por todo o estado, encabeçam a rede que conta ainda com várias unidades do Instituto Federal de ensino técnico (IFG e IF Goiano) e uma vasta rede educacional privada de ensino superior ou técnico (MOURA \& HADDAD, 2015).

A localização central do estado o faz possuir diversos centros de distribuição e um intenso comércio varejista e atacadista instalado, principalmente, em Goiânia, Aparecida de Goiânia e Anápolis, que exercem influência num mercado consumidor que se estende até o Pará. O aglomerado urbano, composto por Brasília (RIDE DF/GO/MG), Goiânia (RM) e Anápolis (Microrregião), é o terceiro mercado consumidor do Brasil ${ }^{4}$ e, por esse motivo, é atrativo de investimentos.

Conforme o Regic 2007 (IBGE), a capital de Goiás e sua rede urbana concentram 363 municípios, que possuem 3,5\% da população e 2,8\% do PIB nacional. Goiânia concentra $30,2 \%$ da população e $29,7 \%$ do PIB da sua rede urbana. A região de influência de Goiânia abrange todo o território do Estado de Goiás e de Tocantins, tendo ainda alguma penetração no Pará, Maranhão, Piauí e Mato Grosso. Outras capitais regionais fazem parte da rede urbana liderada por Goiânia: Palmas (TO) Capital regional B; Araguaína (TO) - Capital regional C; Anápolis (GO), Itumbiara (GO), Rio Verde (GO) e Redenção (PA) - Centros sub-regionais A; e ainda Balsas (MA) e Gurupi (TO) - Centros sub-regionais B.

\footnotetext{
${ }^{4}$ Estevam (2004), Haddad (2011), Miragaya (2000), Siqueira (2009) e Haddad e Moura (2017).
} 


\section{O FORMAL E O REAL, O IMEDIATO E O INTERMEDIARIO: A NOVA PROPOSTA DE DIVISÃO REGIONAL PARA O BRASIL}

Nesta última parte será demonstrada a nova divisão regional proposta pelo IBGE, a partir da análise das dinâmicas existentes no território goiano. Desde que fora adotado pelo IBGE, em 1968, a metodologia de divisão por macrorregião e microrregião geográfica, o estado de Goiás, foi estudado à partir de cinco macrorregiões - Centro Goiano, Leste Goiano, Noroeste Goiano, Norte Goiano e Sul Goiano - que subdividiamse em dezoito microrregiões - São Miguel do Araguaia, Rio Vermelho, Aragarças, Porangatu, Chapada dos Veadeiros, Ceres, Anápolis, Iporá, Anicuns, Goiânia, Vão do Paranã, Entorno de Brasília, Sudoeste de Goiás, Vale do Rio dos Bois, Meia Ponte, Pires do Rio, Catalão e Quirinópolis -, e ainda pela Região Metropolitana de Goiânia, composta por 20 municípios, que, na sua formação, ultrapassava os limites desta divisão microrregional, possuindo municípios pertencentes a diferentes microrregiões. $\mathrm{Na}$ divisão territorial existente em Goiás, ainda tem a RIDE - Região Integrada de Desenvolvimento ${ }^{5}$ - que engloba parte da macrorregião Centro Goiano e Leste Goiano e as microrregiões Vão do Paranã, Chapada dos Veadeiros e Entrono de Brasília, além de todo o Distrito Federal e ainda dois municípios de Minas Gerais.

Em 2017, o IBGE propõe uma nova metodologia para a divisão regional brasileira, com a justificativa de que o país passara por mudanças em sua estrutura produtiva em relação a conjuntura mundial, portanto:

Considerando as mudanças ocorridas na dinâmica econômica do mundo, a inserção do Brasil nos circuitos mundiais, as novas polarizações globais, e tendo em vista, ainda, que o território brasileiro vem passando por intenso processo de transformação, que precisa ser identificado em sua diversidade, é oportuna a construção de um novo modelo de divisão regional para o País. (IBGE, 2017, p. 19).

\footnotetext{
${ }^{5}$ Região integrada de desenvolvimento econômico (RIDE) são áreas análogas às regiões metropolitanas brasileiras, porém contemplam mais de uma unidade federativa e são criadas por lei federal específica. A primeira RIDE implantada foi a do Distrito Federal e Entorno, nos territórios de GO, DF e MG. Posteriormente foram instituídas duas novas RIDEs: Petrolina (PE) e Juazeiro (BA) e Teresina (PI) e Timon (MA).
} 
Com isto, o IBGE reconhece que, a diversidade produtiva do território brasileiro, passa por transformações que levam à necessidade de repensar a divisão regional para além do que já estava estabelecido, pois o formal não representa mais uma dinâmica real e novos espaços surgiram, com conectividades bem mais intensas que as anteriores. As regiões internas do território se conectam para além do que está formalmente estabelecido, criando novas regiões dinâmicas e que se identificam para além da linha imaginaria imposta. De acordo com o IBGE (2017), a região tornou-se uma construção delineada pela dinâmica dos processos de transformações que ocorreram nas últimas três décadas e passou a ser operacionalizada a partir de elementos concretos, que dentre outros, deve-se levar em considerações fatores como a rede urbana, as classificações hierárquicas dos centros urbanos, a detecção de novos fluxos de gestão, que passam a atingir os espaços regionais em escalas adequadas ${ }^{6}$.

Nesta nova proposta de Regiões Geográficas Imediatas e Regiões Geográficas Intermediárias, a Região Imediata tem em sua rede urbana seu principal elemento de referência:

Essas regiões são estruturas a partir de centros urbanos próximos para a satisfação das necessidades imediatas das populações, tais como: compras de bens de consumo duráveis e não duráveis; busca de trabalho; procura por serviços de saúde e educação; e prestação de serviços públicos, como por atendimento do Instituto Nacional de Seguro Social - INSS, do Ministério do Trabalho e de serviços judiciários entre outros. (IBGE, 2017, p. 20).

Por sua vez, as Regiões Geográficas Intermediárias são aquelas que se situam numa "escala intermediaria entre as Unidades da Federação e as Regiões Geográficas Imediatas" (IBGE, 2017, p. 20). São, portanto, regiões não conectadas geograficamente ao centro, mas que se comunicam com ele por diversas dinâmicas. São as Regiões Geográficas Intermediarias que

organizam o território, articulando as Regiões Geográficas Imediatas por meio de um polo de hierarquia superior diferenciado a partir dos fluxos de gestão privado e público e da existência de funções urbanas de maior complexidade, (IBGE, 2017, p. 20)

\footnotetext{
${ }^{6}$ O processo de regionalização fora classificado anteriormente, pelo IBGE, por diversos estudos e metodologias, como: Região de Influencia das Cidades (Regic 2007), Divisão Urbano-Regional (2008), Gestão do Território (2014), Logistica dos Trsnportes do Brasil (2014) e Arranjos Populacionais e Concentrações Urbanas do Brasil (2016).
} 
Ou seja, a Região Imediata é a área de extensão do polo da rede urbana (capitais ou grandes cidades), onde se localizam os principais serviços e decisões. A Região intermediária são as localidades menores, não diretamente unida territorialmente a este polo, ou seja, existe um espaço entre as duas localidades, porém, as dinâmicas econômica e social estão conectadas. São regiões que se ligam não pela unidade territorial, mas pela unidade dos negócios privados e dos serviços públicos.

Nesta metodologia de divisão regional, proposta pelo IBGE em 2017, de regiões imediatas e regiões intermediarias, o estado de Goiás possui seis regiões intermediárias - Goiânia (com 6 regiões imediatas), Itumbiara (com 3 regiões imediatas), Rio Verde (com 3 regiões imediatas), São Luís de Montes Belos - Iporá (com 3 regiões imediatas), Porangatu - Uruaçu (com 3 regiões imediatas) e Luziânia Águas Lindas (com 4 regiões imediatas), conforme quadro abaixo:

Quadro 1 - Regiões Geográficas Intermediarias e Regiões Geográficas Imediatas do Estado de Goiás e números de municípios.

\begin{tabular}{|c|c|c|c|}
\hline Região Geográfica & Número de & Região Geográfica Imediata & Número de \\
\hline \multirow{6}{*}{ Goiânia } & \multirow{6}{*}{80} & Goiânia & 19 \\
\hline & & Anápolis & 18 \\
\hline & & Inhumas - Itaberaí - Anicuns & 13 \\
\hline & & Catalão & 10 \\
\hline & & Goiás - Itapuranga & 15 \\
\hline & & Pires do Rio & 5 \\
\hline \multirow{3}{*}{ Itumbiara } & \multirow{3}{*}{22} & Itumbiara & 8 \\
\hline & & Caldas Novas - Morrinhos & 6 \\
\hline & & Piracanjuba & 8 \\
\hline \multirow{3}{*}{ Rio Verde } & \multirow{3}{*}{29} & Rio Verde & 14 \\
\hline & & Jatai - Mineiros & 10 \\
\hline & & Quirinópolis & 5 \\
\hline \multirow{3}{*}{$\begin{array}{l}\text { São Luís dos Montes Belos - } \\
\text { Iporá }\end{array}$} & \multirow{3}{*}{35} & São Luís dos Montes Belos & 9 \\
\hline & & Iporá & 12 \\
\hline & & Palmeiras de Goiás & 14 \\
\hline \multirow{3}{*}{ Porangatu - Uruaçu } & \multirow{3}{*}{46} & Porangatu & 13 \\
\hline & & Uruaçu - Niquelândia & 10 \\
\hline & & Ceres-Rialma-Goianésia & 23 \\
\hline \multirow{4}{*}{$\begin{array}{l}\text { Luziânia - Águas Lindas de } \\
\text { Goiás }\end{array}$} & \multirow{4}{*}{34} & Luziânia & 6 \\
\hline & & Águas Lindas de Goiás & 7 \\
\hline & & Posse-Campos Belos & 14 \\
\hline & & Flores de Goiás & 7 \\
\hline
\end{tabular}

Fonte: IBGE, 2017.

Para cada região imediata, existem diversas regiões intermediarias, conforme mostra o Quadro 1. Goiânia, a capital e sede da RM, é a região que naturalmente mais 
concentra regiões intermediárias, que dentre elas está a cidade de Anápolis, segundo município em atividade econômica e terceiro em população. Conforme a publicação do IBGE (2017, p. 28), foram criadas:

[...] Região Geográfica Imediata sem um centro articulador claramente definido, objetivando-se a formação de unidades territoriais de divulgação estatística e planejamento territorial. Isso ocorreu, principalmente, no entorno de grandes concentrações urbanas. Como exemplo, cita-se Goiânia/GO, que articula diretamente uma grande área devido a uma macrocefalia relativa. No entorno da cidade, foram criadas três Regiões Geográficas Imediatas sem um centro articulador claramente definido.

As três regiões imediatas, as quais se refere o IBGE, são: o próprio território de extensão de Goiânia, ou seja, parte da RM formal, como Aparecida de Goiânia, Senador Canedo e Trindade, a região de Anápolis, que encabeça uma das microrregiões existentes no estado e Inhumas, Itaberaí e Anicuns, onde, Inhumas, fez parte da RM, desde sua criação, até 2018 , quando saiu da composição da RM e foi substituída por Santa Bárbara.

Goiânia, a capital do estado e a única região metropolitana, lidera todos as dinâmicas do estado em qualquer que for a metodologia adotada. Isolada, como RM, já se destaca como a maior geradora de emprego e renda. Quando estudada na nova metodologia de Região Imediata, continua a englobar municípios como Aparecida de Goiânia, Senador Canedo e Trindade, que possuem produção econômica elevada e que fazem parte da RM. Quando analisada sua Região Intermediaria, anexa a ela a cidade de Anápolis, que possui o segundo PIB do estado. Portanto, a Região Intermediária de Goiânia, assim com a RM formal, continua sendo, de longe, a maior concentradora na geração de empregos e renda (66,5\% dos empregos, em 2017 e 56,5 do PIB de 2015), conforme demonstram as tabelas abaixo: 
Tabela 1 - Total de Empregos da RAIS - RGINT de Goiás - 2017

\begin{tabular}{l|c|c}
\multicolumn{1}{c|}{ Região Geográfica Intermediária - RGINT } & $\mathbf{2 0 1 7}$ & $\%$ \\
\hline RGINT- GOIÂNIA & 1.008 .068 & 66,5 \\
\hline RGINT- ITUMBIARA & 97.816 & 6,5 \\
\hline RGINT- RIO VERDE & 151.984 & 10,0 \\
\hline RGINT- SÃO LUIZ DOS MONTES BELOS - IPORÁ & 50.439 & 3,3 \\
\hline RGINT- PORANGATU-URUAÇU & 79.655 & 5,3 \\
\hline RGINT - LUZIÂNIA-ÁGUAS LINDAS DE GOIÁS & 127.460 & 8,4 \\
\hline TOTAL GOIÁS & $\mathbf{1 . 5 1 5 . 4 2 2}$ & $\mathbf{1 0 0 , 0}$ \\
\hline
\end{tabular}

Fonte: Instituto Mauro Borges (IMB).

A Região intermediária liderada por Goiânia, é disparada a região de Goiás que mais produz vagas de trabalho, seguida, bem de longe, pela Região de Rio de Verde, importante polo do agronegócio brasileiro. Quanto ao Produto Interno Bruto (PIB), a diferença da Região Intermediaria de Goiânia para as demais regiões, cai um pouco, mas ainda assim, a capital concentra mais de $50 \%$ da produção.

Tabela 2 - PIB Valor Adicionado Bruto a Preços Básicos - RGINT Goiás - 2015

\begin{tabular}{l|c|c}
\multicolumn{1}{c|}{ Região Geográfica Intermediária - RGINT } & $\mathbf{2 0 1 5}$ & $\%$ \\
\hline RGINT- GOIÂNIA & 73.513 .873 & 56,5 \\
\hline RGINT- ITUMBIARA & 10.421 .958 & 8,0 \\
\hline RGINT- RIO VERDE & 20.355 .219 & 15,7 \\
\hline RGINT- SÃO LUIZ DOS MONTES BELOS - IPORÁ & 5.380 .415 & 4,1 \\
\hline RGINT- PORANGATU-URUAÇU & 8.692 .619 & 6,6 \\
\hline RGINT - LUZIÂNIA-ÁGUAS LINDAS DE GOIÁS & 11.769 .534 & 9,1 \\
\hline TOTAL GOIÁS & $\mathbf{1 3 0 . 0 3 3 . 6 1 8}$ & $\mathbf{1 0 0 , 0}$ \\
\hline
\end{tabular}

Fonte: IBGE

A Região Intermediária de São Luís de Montes Belos e Iporá, da qual faz parte a cidade de Palmeiras de Goiás, é imediatamente conectada à Região Metropolitana. Palmeiras de Goiás faz divisa com Trindade e Santa Bárbara de Goiás e possui dinâmica econômica totalmente atrelada à capital. Historicamente, São Luís de Montes 
Belos e Iporá, são polos agrários, na região do Araguaia e o crescimento das atividades desses municípios sempre ocorreram de maneira semelhante.

O destaque nessa nova divisão parece ser para a cidade de Anápolis, que mesmo tendo perdido em população e número de eleitores, para Aparecida de Goiânia, desde o censo de 2000, continua a ser importante polo econômico, mantendo sua posição de segundo lugar no PIB e de região de influencia imediata, tendo em vista que, pelo que indica o IBGE, em números de cidades, Anápolis tem região imediata composta por dezoito cidades, praticamente igual ao da Capital, que tem dezenove. Ou seja, o raio de influência de Anápolis, dentro do estado de Goiás, é idêntico ao da capital e ao unir as duas cidades, numa região geográfica apenas, os números, dessa região, eleva-se bastante, conforme demonstrou as tabelas 1 e 2 .

O sul de Goiás historicamente é uma região rica, mas não tão rica como se tornou o centro do estado após a criação de Goiânia ${ }^{7}$. A ligação do sul goiano com Minas Gerais, sempre foi fator que impulsionou a economia local, fazendo surgir polos como Catalão, Itumbiara e Rio Verde. Esta última, torna-se, na virada do século XX para XXI, importante polo do agronegócio, por sua localização na Região Centro Oeste, ou seja, caminho para Mato Grosso. Atualmente, Rio Verde lidera a rede comercial de todo o sudoeste goiano e consequentemente, encabeça a cadeia d o agronegócio no Centro - Oeste.

Itumbiara, no sul goiano, por sua vez, fica na divisa com Minas Gerais e concentra em seu território importantes agroindústrias, dentre elas, a maior empresa do agronegócio goiano ${ }^{8}$. Mais ao leste, no sudeste goiano, está Catalão, cidade que fora beneficiada pela passagem da estrada de ferro, conectando-a diretamente à Anápolis, ainda no início do século passado, funcionando como entreposto entre Anápolis e o Triângulo Mineiro ${ }^{9}$. Junto com Rio Verde e Itumbiara, Catalão, que fica no chamado Sul Goiano, compõe a lista de três importantes cidades que, além de beneficiadas pelos

\footnotetext{
7 Importante ressaltar que, mesmo o sul de Goiás historicamente ser uma região rica por sua ligação direta com a Região Sudeste, a economia de Anápolis, com a chegada da estrada de ferro, no inicio do século passado, ultrapassara o sul, fato que fora potencializado com a criação de Goiânia e Brasília, em meados do mesmo século.

${ }^{8}$ A Indústria de Alimentos Caramuru, originaria do Paraná, tem sua maior fábrica em Itumbiara, se beneficiando das Rodovias e da Hidrovia que passam pela região.

${ }^{9}$ Com a chegada da estada de ferro, Anápolis torna-se o local da comercialização da safra de cereais da CANG. A estrada de ferro que passava por Catalão, favoreceu o surgimento de diversas atividades econômicas em suas imediações, das quais, Catalão concentrou diversos curtumes.
} 
investimentos privados, também receberam investimentos públicos sendo bastante beneficiadas pela política de incentivos fiscais concedida pelo governo estadual. Rio Verde e Itumbiara concentram agroindústrias e serviços voltados para tal finalidade. Catalão possui duas indústrias automobilísticas e outras de exploração mineral, sendo um grande produtor de nióbio.

O norte goiano sempre foi a região mais atrasada, quando se refere a questões de desenvolvimento econômico. Após a divisão do estado, em 1989, o Norte passou as ser a região onde se localizam Minaçu e Porangatu, cuja atividade principal, desde a criação do estado de Goiás, foi a pecuária, depois, aos poucos, a produção de soja foi tomando espaço. Mas uma atividade econômica desenvolveu-se paralelamente à pecuária e a agricultura no norte de Goiá, que é a exploração mineral. Minaçu é um dos maiores produtores mundiais de amianto.

Niquelândia, como o próprio nome indica, foi forte na produção de Níquel. Já em Goianésia, a atividade econômica principal é a produção de derivados da cana de açúcar. A cidade possui diversas usinas de etanol, já tendo ocupado o posto de maior produtor do estado. Ceres e Rialma, cidades gêmeas, divididas apenas pelo Rio das Almas, ficam às margens da BR 153 e surgiram da criação da CANG, tornando-se importantes produtoras de ceareis, concentradoras de comercio e hoje sobrevivem do agronegócio conectado diretamente com Goianésia, Uruaçu, Anápolis e Goiânia.

A região geografia mais complexa de Goiás é a que circunda o Distrito Federal. Esta região, que o governo goiano chama de Entorno do DF, sempre sofreu pela falta de investimentos públicos. Criou-se, com isso, a mais fragilizada região do estado, pois a falta de investimentos públicos se fez acompanhada por um vertiginoso crescimento populacional composto pelos "excluídos do DF". População que, não conseguindo se fixar nas caras terras do Distrito Federal, passou a habitar o território goiano (o entorno), causando os mais diversos problemas que podem ocorrem quando há o encontro de uma crescente população e a total ausência de políticas públicas.

Este Entorno do DF, região que compõe a Ride, também é estudada como Arranjo Urbano-Regional Brasília - Anápolis - Goiânia (Haddad e Moura, 2017). O que hora foi chamado de Eixo Goiânia - Anápolis - Brasília (Haddad, 2011), passou a ser entendido como um arrojado arranjo urbano regional que conecta a Região 
Metropolitana de Goiânia, com a microrregião de Anápolis e a Ride, que como já mencionado, engloba a parte de Goiás que contorna o DF, o próprio Distrito Federal e ainda dois municípios de Minas Gerais.

$\mathrm{Na}$ concepção de Região Geográfica Intermediaria, a junção de Anápolis a Goiânia e à Região de Brasília, demonstra o que já vem sendo estudado para esta região. Não existe linha imaginaria capaz de impedir os avanços das dinâmicas sociais e econômicas. A versatilidade das atividades econômicas e da visa em sociedade ocorrem naturalmente sem barreiras que a impeçam de adentrar territórios.

No sistema capitalista e ainda mais na era da tecnologia, não há barreira capaz de segurar o ímpeto dos investimentos que buscam por mais lucros. Neste sentido, a região é uma mesma arena onde atores realizam transações econômicas, relações políticas e sociais, é um território que se estende ultrapassando fronteiras, o que significa que o planejamento deve pensar para além do que formalmente fora estabelecido e respeitar o que realmente está estabelecido.

\section{CONSIDERAÇÕES FINAIS}

O estado de Goiás, durante o processo de integração da economia nacional, foi inserido como produtor de matérias primas. Pela distância e isolamento das regiões mais desenvolvidas, e pelas dificuldades de acesso. A chegada da ferrovia, no início do século $\mathrm{XX}$, representou contato mais rápido com a modernidade existente nos grandes centros. Aos poucos, seu perfil econômico transforma-se. Goiás foi diretamente beneficiado pelas políticas federais voltadas para a integração do território nacional, entre as décadas de 1940 a 1970. O estado de Goiás foi um dos mais beneficiados pela interiorização da indústria. Enquanto estados mais industrializados perderam, Goiás cresceu na participação industrial. Este processo criou novas áreas dinâmicas dentro do estado, que foram impulsionadas pela política de incentivos fiscais do governo estadual.

A economia de Goiás nunca perdeu sua tradição agraria. Mesmo tendo transformado nas últimas décadas, a indústria que cresce em Goiás, é a que depende da sua produção agrícola e pecuária. O sul goiano, por localizar-se em região imediata ao triângulo mineiro, foi a primeira a primeira a se destacar na potencialidade 
econômica, sendo posteriormente superada pelo centro goiano, que passou a contar com o impulso da ferrovia, em Anápolis, e depois pelo surgimento de Goiânia e Brasília.

Como capital, Goiânia passou a concentrar as principais atividades econômicas, além de ser o centro das decisões. À medida que as atividades cresceram, conectaramse à Brasília, passando por Anápolis, onde já existia e também se instalou novas e diversificadas atividades econômicas.

A nova metodologia proposta pelo IBGE, parece reconhecer que os territórios não possuem muros que limitam suas dinâmicas. Os territórios se complementam e são áreas de expansão, sejam de maneira imediata ou intermediaria. E neste contexto, para Goiás, a capital e sua região metropolitana, adicionada a Anápolis, formam uma área que chega até a divisa com o Distrito Federal, onde se concentra mais da metade da geração de empregos e riquezas, comprovando o que os estudos de geografia e economia regional já apontam: o sistema capitalista, aliado à falta de planejamento, favorece a uma realidade de alta concentração populacional, de geração de empregos e de produção.

Especificamente no território goiano, estudos anteriores já apontavam para a existência de uma dinâmica no denominado "arranjo urbano regional Brasília - Anápolis - Goiânia", e ainda no sul e sudoeste goiano. Estas são regiões que, nitidamente, indicam para uma interrelação econômica que ultrapassa a, até então, divisão formal existente. Esta nova metodologia adotada pelo IBGE vem, de maneira oficial, reconhecer o que estes estudados já perceberam.

Com isso, confirma-se que a dinâmica territorial não possui limites. Não existem barreiras imaginárias que limitam a expansão econômica ou social. A força das leis, que separam as regiões, sem observar identidades e dinâmicas recíprocas, não é capaz de limitar os avanços da expansão econômica. É certo que análises mais profundas ainda precisam ser feitas, além das simplórias observações deste pequeno ensaio, mas esta nova divisão proposta pelo IBGE, abre espaço para que tais observação sejam justas ao que é a dinâmica real, ao que verdadeiramente acontece na região. 


\section{REFERÊNCIAS BIBLIOGRÁFICAS}

BORGES, P. C. A. Formação e Representação do Estado em Goiás. In: SOUZA, D. B. (Org.). Goiás: Sociedade \& Estado. Goiânia: Cânone Editora, 2004.

CASTILHO, D. A Dinâmica Socioespacial de Ceres/ Rialma no Âmbito da Modernização de Goiás: território em movimento, paisagens em transição. Dissertação de Mestrado. Universidade Federal de Goiás - IESA. Goiânia, 2009.

CUNHA, L.A.G. Sobre o conceito de região. Revista de História Regional. n.2 (5), Ponta Grossa, PR, 2000.

ESTEVAM, L. O Tempo da Transformação. Goiânia: Ed. UCG/Vieira, 2004.

FIRKOWSKI, O. L. C. F. org. Transformações Territoriais experiências e desafios. Rio de Janeiro: Letra Capital, 2010.

GOIÁS - Secretaria de Estado de Infra-Estrutura. Plano de Desenvolvimento do sistema de Transportes do Estado de Goiás. Goiânia, 2007.

HADDAD, M. B. Eixo Goiânia-Anápolis-Brasília: estruturação, interrupção e retomada das políticas públicas. Dissertação de Mestrado. PUC-GO. Goiânia, 2011.

HADDAD, M. B. MOURA, R. Dinâmicas da expansão do arranjo urbano-regional Brasília-Anápolis-Goiânia. Novas Edições Acadêmicas. 2017.

IBGE. Região de Influência das Cidades. Rio de Janeiro: IBGE, 2007.

IBGE. Divisão regional do Brasil em regiões geográficas imediatas e regiões geográficas intermediárias. Rio de Janeiro: IBGE,2017.

MIRAGAYA. J. A Região de Brasília-Goiânia: Formação, Problemas e Potencialidades. Revista de Conjuntura. n. 5, jan/mar, 2000.

MOURA, R.; HADDAD, M. B. O arranjo urbano-regional Brasília-Anápolis-Goiânia. Revista Bibliográfica de Geografia y Ciencias Sociales. v. XX, n. 1119, Barcelona, 2015. PACHECO, C. A. Fragmentação da nação. Campinas: IE-Unicamp, 1998.

SIQUEIRA, E. B. O Desenvolvimento do Estado de Goiás sob a ótica do planejamento territorial. Revista CEPPG, n. 20, v. 1/2009, pp. 101-114, 2009. 